\section{Hong Kong Criminal Procedure}

This book sets out the basic principles and practices of criminal procedure in Hong Kong, which are still to a large extent based on the laws of England and Wales. Criminal procedure in Hong Kong is best understood in the context of legal developments in England and Wales and other Commonwealth jurisdictions, notably Canada and Australia. However, criminal procedure in Hong Kong is not simply a derivative of English law; political and legal changes effected by the handover of Hong Kong to the Peoples' Republic of China in 1997, and the concomitant advent of law reforms initiated by the government of the Hong Kong Special Administrative Region are also fully reflected in this text. This book is the first volume in a series on criminal justice in Hong Kong - the other titles being on the law of evidence and criminal law (general principles and specific offences). The cross-references in the three volumes underscore the practical and theoretical interplay between the three subject areas, which will prove indispensable for academics, students, and practitioners alike.

Q. Wolters Kluwer

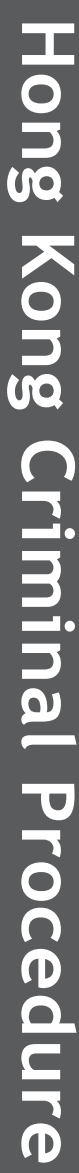

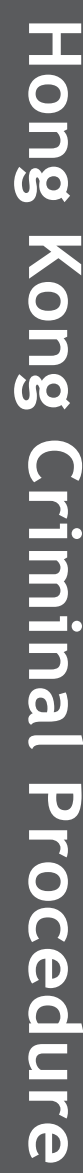

3
$\frac{1}{3}$
0
0
0
0
0
$\frac{1}{1}$
$\frac{1}{0}$
3
0
0
Hong Kong Criminal Procedure

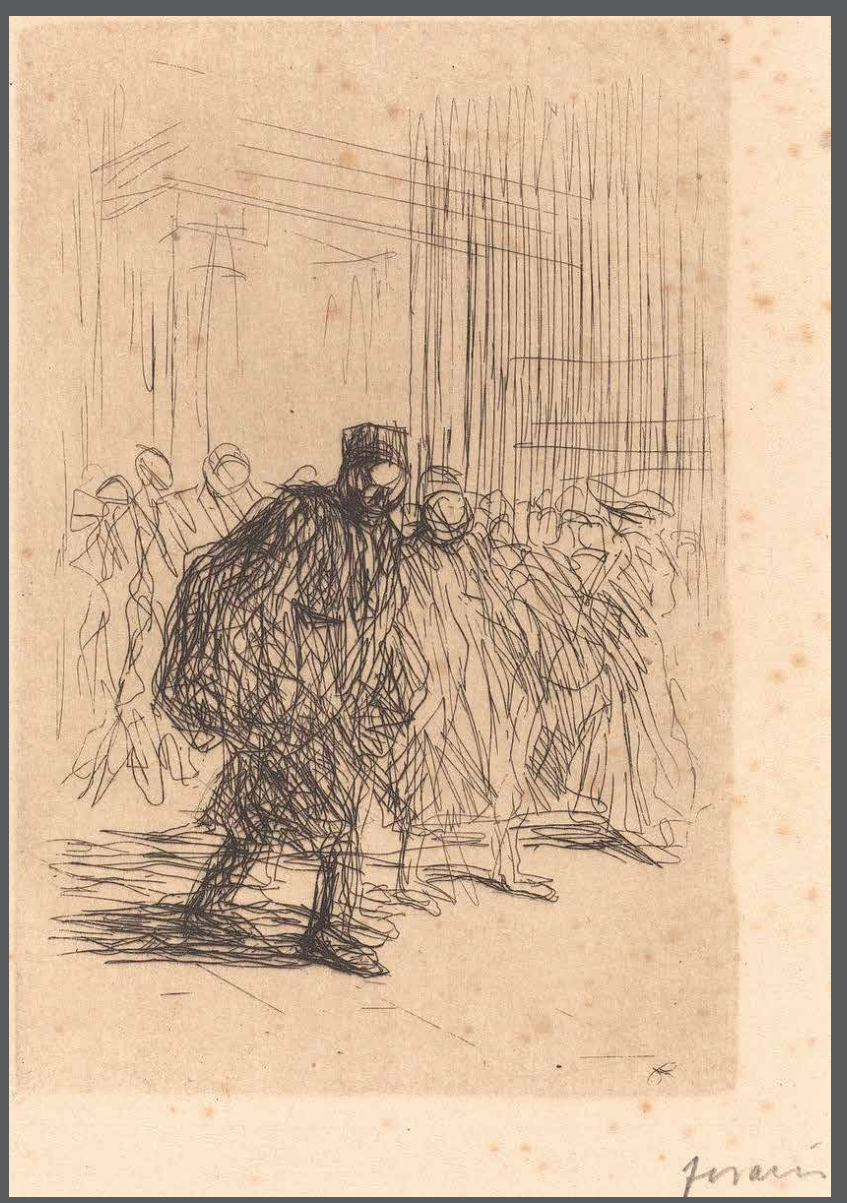

Andra le Roux-Kemp

O. Wolters Kluwer 